\title{
ANAPHYLAXIS TO PANTOPRAZOLE IN A CHILD
}

\author{
Sonia de Arriba ${ }^{1}$, Jesús Martín Valbuena ${ }^{1}$, Laura Sanz Rueda ${ }^{1}$, Miriam Sobrino-García ${ }^{1}$, \\ Alicia Gallardo Higueras ${ }^{1}$, Rosita Castillo Loja ${ }^{1}$, Eva Macías ${ }^{1}$, Cristina Martín García ${ }^{1}$, \\ Esther Moreno ${ }^{1}$, Francisco Muñoz-Bellido ${ }^{1}$, María Teresa Gracia Bara ${ }^{1}$, Elena Laffond ${ }^{1}$, \\ and Ignacio Dávila ${ }^{1}$ \\ ${ }^{1}$ University Hospital of Salamanca
}

December 6, 2021

\section{ANAPHYLAXIS TO PANTOPRAZOLE IN A CHILD}

Arriba-Méndez $\mathrm{S}^{2,3}$ MD PhD, Martin-Valbuena J2 MD, Sanz-Rueda L ${ }^{2}$ MD, Sobrino-García M ${ }^{1,3}$ MD PhD, Gallardo-Higueras $\mathrm{A}^{1} \mathrm{MD}$, Castillo-Loja $\mathrm{R}^{1} \mathrm{MD}$, Macías E, ${ }^{1,3} \mathrm{MD}$ PhD Martín $\mathrm{C}^{1,3} \mathrm{MD}$ PhD, Moreno E ${ }^{1,3,4}$ MD PhD, Muñoz-Bellido FJ ${ }^{1,3}$ MD PhD, Gracia-Bara $\mathrm{MT}^{1,3} \mathrm{MD}$, Laffond $\mathrm{E}^{1,3} \mathrm{MD}$ PhD, Dávila $\mathrm{I}^{1,3,4} \mathrm{MD}$ $\mathrm{PhD}$.

1. Department of Allergy, University Hospital of Salamanca, Salamanca, Spain

2. Department of Pediatrics, University Hospital of Salamanca, Salamanca, Spain

3. Institute for Biomedical Research of Salamanca, IBSAL, Salamanca, Spain

4. Asthma, Allergic and Adverse Reactions (ARADyAL) Network for Cooperative Research in Health of Instituto de Salud Carlos III, Hospital Universitario de Salamanca, Salamanca, España.

Key words: Proton pump inhibitors. Pantoprazole. Hypersensitivity. Child. Anaphylaxis.

To the Editor,

Pantoprazole and its analogs (omeprazole, esomeprazole, lansoprazole, rabeprazole) are potent proton pump inhibitors (PPIs), whose use is increasing in the pediatric population (1). They are prescribed for several gastrointestinal pathologies (2), particularly gastroesophageal reflux disease (GERD), but also duodenal ulcers, non-steroidal anti-inflammatory-induced ulcer-related prophylaxis, Helicobacter pylori infection, eosinophilic esophagitis, and other diseases. In general, they have an excellent safety profile, and adverse effects are mild and infrequent (1-3\% of patients)(1).

Hypersensitivity reactions to PPIs are mainly IgE-mediated, but non-IgE-mediated [contact dermatitis, toxic epidermal necrolysis, leukocytoclastic vasculitis or Drug Reaction with Eosinophilia and Systemic Symptoms (DRESS)] have been described. In children, immediate hypersensitivity reactions have only been exceptionally reported (3).

We introduce the case of a five-year-old girl with a medulloblastoma diagnosed at the age of 3 years, undergoing radiotherapy treatment (last session ten days ago) who was referred to our Allergology Service after suffering an episode of anaphylaxis. Previously to each session, she received premedication with ondansetron plus pantoprazole. In the last session, she had just received ondansetron intravenously and a few minutes after starting the pantoprazole infusion, a generalized diffuse erythematous exanthema suddenly erupted. The event was followed by coughing, severe dyspnea, and inspiratory stridor. No consciousness decrease was reported, neither vomiting nor other gastrointestinal symptoms. Acute anaphylaxis was diagnosed, and the patient was treated with intramuscular epinephrine $(0.01 \mathrm{mg} / \mathrm{kg})$, intravenous systemic corticosteroids $(1 \mathrm{mg} / \mathrm{kg})$, and dexchlorpheniramine with gradual resolution in half an hour. The patient had previously 
received ondansetron and pantoprazole without presenting any adverse reaction. There was neither family nor personal background of hypersensitivity reactions or atopic disease.

Skin prick-tests with solutions of non-irritating concentrations (4) of ondansetron $(2 \mathrm{mg} / \mathrm{ml})$, pantoprazole $(40 \mathrm{mg} / \mathrm{ml})$, omeprazole $(40 \mathrm{mg} / \mathrm{ml})$ and lansoprazole $(30 \mathrm{mg} / \mathrm{ml})$ were all negative, i.e., the wheal maximum diameter was less than $3 \mathrm{~mm}$ over the saline control. Intradermal tests (IDTs) with ondansetron $(0.002 \mathrm{mg} / \mathrm{ml}$ and $0.01 \mathrm{mg} / \mathrm{ml})$ were negative, but IDTs with pantoprazole $(4 \mathrm{mg} / \mathrm{ml})$ and omeprazole $(4 \mathrm{mg} / \mathrm{ml})$ were positive. A single-blind placebo-controlled oral challenge test with ondansetron was performed, showing tolerance of a $3 \mathrm{mg}$ dose.

A diagnosis of anaphylaxis for pantoprazole was established. Tolerance to lansoprazole was not considered, due to the previous life-threatening reaction, but, it could be considered in the future if required. All proton pumps inhibitors were formally contraindicated.

Despite the increase in PPI prescription in pediatric patients, a rise in immune-mediated reactions has not been detected, but there are few studies evaluating PPI allergy in children (5). To date, three cases of PPI anaphylaxis have been described in the pediatric population. One of them was an adolescent studied at 16 who had had anaphylaxis with omeprazole three years earlier. Prick and intradermal tests with omeprazole (0.4 and $4 \mathrm{mg} / \mathrm{ml})$, pantoprazole $(0.4$ and $4 \mathrm{mg} / \mathrm{ml})$ were negative, but she had a positive challenge with pantoprazole, reproducing anaphylaxis (6). That same year, probable anaphylaxis due to omeprazole and esomeprazole was also described in a 4-month-old infant who presented several episodes of respiratory distress, alongside facial edema in some of them, after using these drugs; however, no allergy study was performed (7). The final described case (8) is a 14-year-old male that had anaphylaxis with omeprazole. Skin prick test were negative, but intradermal tests with omeprazole and lansoprazole were positive. The authors did not perform skin tests with pantoprazole.

Ours is the fourth published case of PPI anaphylaxis in children, being the youngest reported patient in which intradermal tests demonstrated an IgE-mediated hypersensitivity reaction. In the literature, cross-reactivity patterns among PPIs have described (9): selective sensitization to a single PPI, whole-group hypersensitivity, omeprazole-esomeprazole-pantoprazole hypersensitivity, and lansoprazole-rabeprazole hypersensitivity. In addition, there are published cases that do not fit those patterns (10). Any case, in PPI-mediated IgE allergy, skin tests have proven useful for diagnosis as they have high specificity and positive predictive value, although low sensitivity (10).

In a suspected allergy to a PPI, preventive withdrawal of all PPIs can be appropriate in managing these patients, but we consider that skin tests should always be performed. If negative, controlled oral provocation tests with the PPIs that displayed negative results should always be considered, acknowledging the riskbenefit ratio and possible cross-reactivity patterns.

\section{References}

1. Mori F, Franceschini F, Saretta F, Bianchi A, Bottau P, Caimmi S, et al. Hypersensitivity reactions to proton pump inhibitors in childhood. Pediatr Allergy Immunol. 2020;31(S26):29-32.

2. Illueca M, Alemayehu B, Shoetan N, Yang H. Proton pump inhibitor prescribing patterns in newborns and infants. J Pediatr Pharmacol Ther JPPT Off J PPAG. 2014;19(4):283-7.

3. Pasman EA, Ong B, Witmer CP, Nylund CM. Proton Pump Inhibitors in Children: the Good, the Bad, and the Ugly. Curr Allergy Asthma Rep. 2020 Jun;20(8):39.

4. Bonadonna P, Lombardo C, Bortolami O, Bircher A, Scherer K, Barbaud A, et al. Hypersensitivity to proton pump inhibitors: diagnostic accuracy of skin tests compared to oral provocation test. Vol. 130, The Journal of allergy and clinical immunology. United States; 2012. p. 547-9.

5. Özdemir SK, Bavbek S. Hypersensitivity reactions to proton-pump inhibitors: Clinical presentation, diagnosis, and management. Allergy Asthma Proc. 2020;41(2):E37-44. 
6. Reyes Balaguer J, Campos Andreu A, Hernández Fernández de Rojas D. [Anaphylaxis to proton pump inhibitors]. Vol. 128, Medicina clinica. Spain; 2007. p. 799.

7. Baldassarre E, Sagaon MM, Ferrarini A, Bianchetti MG. Severe systemic adverse reaction to proton pump inhibitors in an infant. Pediatr Pulmonol. 2007 Jun;42(6):563-4.

8. Tayman C, Mete E, Catal F, Tonbul A. Hypersensitivity reaction to omeprazole in a child. J Investig Allergol Clin Immunol. 2009;19(1):76-7.

9. Lombardo C, Bonadonna P. Hypersensitivity Reactions to Proton Pump Inhibitors. Curr Treat Options Allergy [Internet]. 2015;2(2):110-23. Available from: https://doi.org/10.1007/s40521-015-0046-0

10. Kepil Özdemir S, Yilmaz I, Aydin Ö, Büyüköztürk S, Gelincik A, Demirtürk M, et al. Immediate-type hypersensitivity reactions to proton pump inhibitors: Usefulness of skin tests in the diagnosis and assessment of cross-reactivity. Allergy Eur J Allergy Clin Immunol. 2013;68(8):1008-14. 